\title{
Modifikasi Perencanaan Apertemen Grand Kamala Lagoon Menggunakan Struktur Baja Komposit dengan Sistem Rangka Berpengaku Eksentris
}

\author{
Ahmad Zaky, Endah Wahyuni dan Isdarmanu \\ Departemen Teknik Sipil, Fakultas Teknik Sipil \& Perencanaan, Institut Teknologi Sepuluh Nopember \\ e-mail: endah@ce.its.ac.id
}

\begin{abstract}
Abstrak-Salah satu sistem alternatif penahan gempa yaitu menggunakan material baja komposit dengan Sistem Rangka Berpengaku Eksentris. Sistem Rangka Berpengaku Eksentris merupakan sistem dimana pengaku tidak terhubung ke perpotongan balok dan kolom melainkan terhubung ke balok dengan jarak " $e$ " ke titik perpotongan balok dan kolom. Segmen balok pendek atau link ini memiliki daktilitas yang tinggi yang memastikan struktur memiliki perilaku inelastis serta penyerapan energi yang baik. Kinerja dari balok link tersebut akan lebih maksimal jika elemen-elemen diluar balok link tersebut direncanakan lebih kuat. Modifikasi perencanaan yang dilakukan pada Apartemen Grand Kamala Lagoon ini yaitu menggunakan struktur baja komposit dengan sistem rangka berpengaku eksentris. Perhitungan struktur yang dilakukan pada perencanaan tersebut mengacu kepada SNI03-1729-2015 "Spesifikasi untuk Bangunan Gedung Baja Struktural", SNI-03-1729-2015 "Tata Cara Perencanaan Ketahanan Gempa untuk Struktur Gedung dan Non Gedung”, SNI-03-1727-2013 "Beban Minimum untuk Perancangan Bangunan Gedung dan Struktur Lain", PPIUG 1983, dan SNI03-2847-2013 "Persyaratan Beton Struktural untuk Bangunan Gedung”. Permodelan dan analisa struktur menggunakan program bantu ETABS 2016. Dari hasil analisa yang telah dilakukan, diperoleh tebal pelat atap dan lantai $11 \mathrm{~cm}$, dimensi balok induk arah $X$ dan $Y$ yaitu WF600.300.12.17 dan WF600.300.14.23, dimensi kolom yaitu HSS700.700.28, dimensi bresing yaitu WF300.300.15.15, dimensi link yaitu WF700.300.13.24 dengan panjang link $120 \mathrm{~cm}$, baseplate menggunakan fixed plate 900.900.60, dari Continental Steel. Sambungan struktur utama direncanakan sambungan kaku menggunakan baut mutu tinggi A490. Pondasi menggunakan tiang pancang berdiameter $60 \mathrm{~cm}$ dengan kedalaman $22 \mathrm{~m}$. Balok Tie Beam dimensi 450x650 mm dipasang tulangan utama 5D16 dan tulangan geser Ø10-300.
\end{abstract}

Kata Kunci-Sistem Rangka Berpengaku Eksentris, Link, Baja, Komposit.

\section{PENDAHULUAN}

$\mathrm{P}$ ESATNYA perkembangan jumlah penduduk di Indonesia berdampak pada kebutuhan lahan hunian yang semakin tinggi dengan keterbatasan lahan yang ada. Hal tersebut mengakibatkan kebutuhan akan gedung atau apartemen semakin meningkat dan merata di seluruh kotakota besar di Indonesia. Pada umumnya, pembangunan gedung atau apartemen di Indonesia menggunakan struktur beton bertulang. Sedangkan, kondisi wilayah di Indonesia termasuk kedalam zona Ring of Fire dimana terdapat banyak aktifitas seismik atau gempa bumi sehingga penggunaan struktur beton bertulang yang umum digunakan dalam gedung bertingkat cukup beresiko. Oleh karena itu, sistem yang lebih baik yang seharusnya digunakan dalam pembangunan gedung bertingkat yaitu sistem konstruksi baja komposit sebagai salah satu sistem alternatif penahan gempa.

Salah satu kriteria dalam merancang struktur bangunan tinggi terutama untuk gedung adalah keselamatan (strength and ductile) dan kenyamanan (stiffness). Baja memiliki semua hal tersebut, dimana karakteristik baja identik dengan kekerasan, kekakuan, kekuatan tarik yang tinggi dan juga daktilitas. Penggunaan material baja dalam konstruksi merupakan suatu alternatif yang menguntungkan berdasarkan pertimbangan ekonomi, sifat, dan kekuatannya dalam memikul beban terutama beban lateral seperti gempa bumi [1]. Selain itu, sifat daktail yang dimiliki material baja dapat memberi perubahan bentuk yang besar sebelum mencapai kehancuran. Salah satu bangunan baja yang dirancang tahan gempa adalah bangunan baja dengan menggunakan sistem struktur berpengaku eksentris.

Sistem Rangka Berpengaku Eksentris (SRBE) adalah sistem dimana pengaku tidak terhubung ke perpotongan balok dan kolom melainkan terhubung ke balok dengan jarak "e" ke titik perpotongan balok dan kolom. Segmen balok pendek atau link ini memiliki daktilitas yang tinggi yang memastikan struktur memiliki perilaku inelastis serta penyerapan energi yang bagus [2]. Kinerja dari balok link tersebut akan lebih maksimal jika elemen-elemen di luar dari balok link tersebut direncanakan lebih kuat. Konsep perencanaan SRBE yang berdasarkan keseimbangan mekanisme kelelehan akan mencegah terjadinya cara keruntuhan yang tidak diinginkan yaitu elemen-elemen struktur tidak mengalami penurunan kekakuan dan kekuatan saat struktur menerima beban lateral [3].

Dalam pengerjaan studi ini, akan dilakukan modifikasi gedung Apartemen Grand Kamala Lagoon yang berlokasi di kota Bekasi. Apartemen Grand Kamala Lagoon merupakan gedung dengan struktur utama beton bertulang dengan ketinggian 46 lantai. Apartemen tersebut akan dibangun lagi bersebelahan dengan lokasi sebelumnya namun hanya membutuhkan ketinggian 23 lantai dan menggunakan struktur komposit dengan sistem rangka berpengaku eksentris dengan konfigurasi rangka inverted $V$-braced.

\section{TINJAUAN PUSTAKA}

Sistem Rangka Berpengaku Eksentris (SRBE) merupakan suatu sistem struktur yang terdiri atas balok, kolom, dan pengaku dimana pengaku tersebut tidak terhubung ke perpotongan balok dan kolom melainkan terhubung ke balok dengan jarak "e" ke titik perpotongan balok dan kolom. Segmen balok pendek atau link ini memiliki daktilitas yang tinggi yang memastikan struktur memiliki perilaku inelastis serta penyerapan energi yang 
bagus [2]. Kinerja dari balok link tersebut akan lebih maksimal jika elemen-elemen di luar dari balok link tersebut direncanakan lebih kuat. Konsep perencanaan SRBE yang berdasarkan keseimbangan mekanisme kelelehan akan mencegah terjadinya cara keruntuhan yang tidak diinginkan yaitu elemen-elemen struktur tidak mengalami penurunan kekakuan dan kekuatan saat struktur menerima beban lateral.

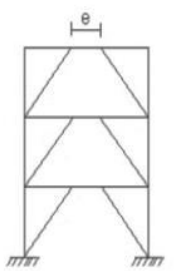

b. Split-K-braced EBF

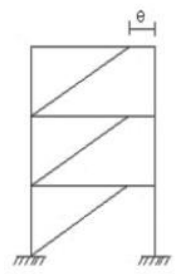

a. D-braced EBF

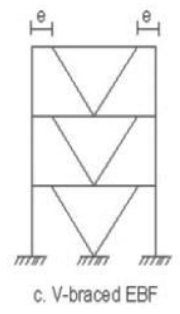

Gambar 1. Jenis-Jenis Konfigurasi SRBE [4].
Link beam merupakan elemen balok pendek yang direncanakan mengalami kelelehan lebih awal pada saat bekerjanya beban lateral pada struktur. Pada bagian link ini bekerja gaya geser (shear) pada kedua ujung link dengan besar yang sama dan arah yang berlawanan. Gaya geser yang bekerja tersebut mengakibatkan momen pada kedua ujung link dengan besar dan arah yang sama, sehingga didapatkan persamaan $\mathrm{Ve}=2 \mathrm{M}$. Pada kasus ini link diasumsikan hanya dalam keadaan plastis biasa, tidak pada saat strain hardening dan tidak ada interaksi antara momen dan geser. Dalam keadaan tersebut, maka dapat dirumuskan sebagai berikut

$$
e=\frac{2 M p}{V_{p}}
$$
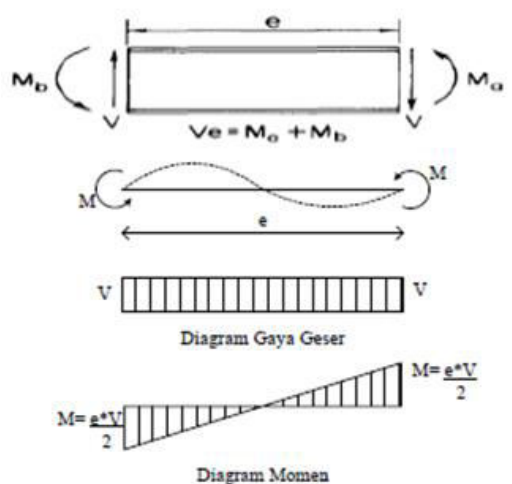

Gambar 2. Gaya yang Bekerja Pada Link [5].

Menurut Engelheardt (2007) [6], pada design struktur penahan gempa dengan SRBE perlu diperhitungkan besar rotasi plastis yang akan dialami oleh link. Pada tahap ini lebih mudah menggunakan mekanisme disipasi energi (juga disebut mekanisme kehancuran). Gambar 3 menunjukkan mekanisme kehancuran dari SRBE. Pada setiap kasus $\theta$ merupakan besar penyimpangan yang terjadi pada rangka, besar penyimpangan pada sendi plastis terhadap balok juga disimbolkan $\theta$. Untuk SRBE besar dari kebutuhan rotasi link $(\gamma)$ harus lebih besar dari $\theta$, dengan perumusan:

$$
\gamma=\frac{\mathbf{L}}{\mathrm{e}} \boldsymbol{\theta}
$$

Dimana:

$\gamma=$ Rotasi link
$\mathrm{L}=$ Panjang balok

$\mathrm{e}=$ Panjang link

$\theta=$ Besar penyimpangan struktur

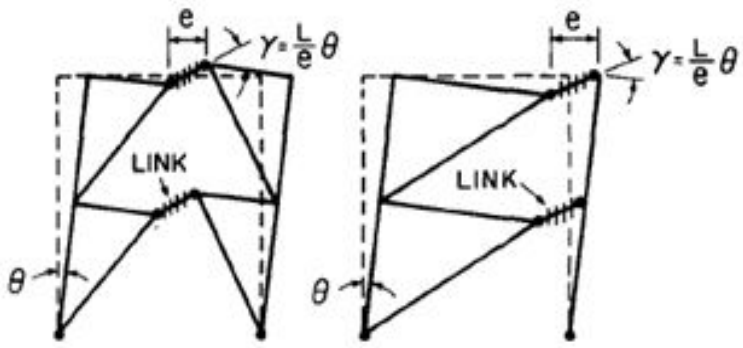

Gambar 3. Mekanisme Energi Disipasi [5].

Klasifikasi jenis link terhadap panjang link, rotasi yang terjadi pada link dan jarak pengaku maksimum adalah sebagai berikut,

Tabel 1.

Klasifikasi Link [7]

\begin{tabular}{|c|c|c|c|c|}
\hline No & Panjang link & Jenis Link & Rotasi & $\begin{array}{c}\text { Jarak Pengaku } \\
\text { Maksimum }\end{array}$ \\
\hline \multirow{2}{*}{1} & $e \leq \frac{1,6 \times M p}{V_{p}}$ & Geser & 0,08 & 30. tw $-\mathrm{d} / 5$ \\
\cline { 3 - 5 } 2 & $\frac{1,6 \times M p}{V_{p}} \leq e \leq \frac{2,6 \times M p}{V_{p}}$ & Dominnan Geser & & 1 dan 3 dipenuhi \\
\hline 3 & $\frac{2,6 \times M p}{V_{p}} \leq e \leq \frac{5 \times M p}{V_{p}}$ & Dominan Lentur & 0,02 & 1,5 bf dari tiap ujung link \\
\hline 4 & $e>\frac{5 \times M p}{V_{p}}$ & Lentur Murni & & Tidak memerlukan \\
\hline
\end{tabular}

\section{METODOLOGI}

Urutan penyelesaian Studi ini dapat dilihat pada bagan alir dibawah ini:

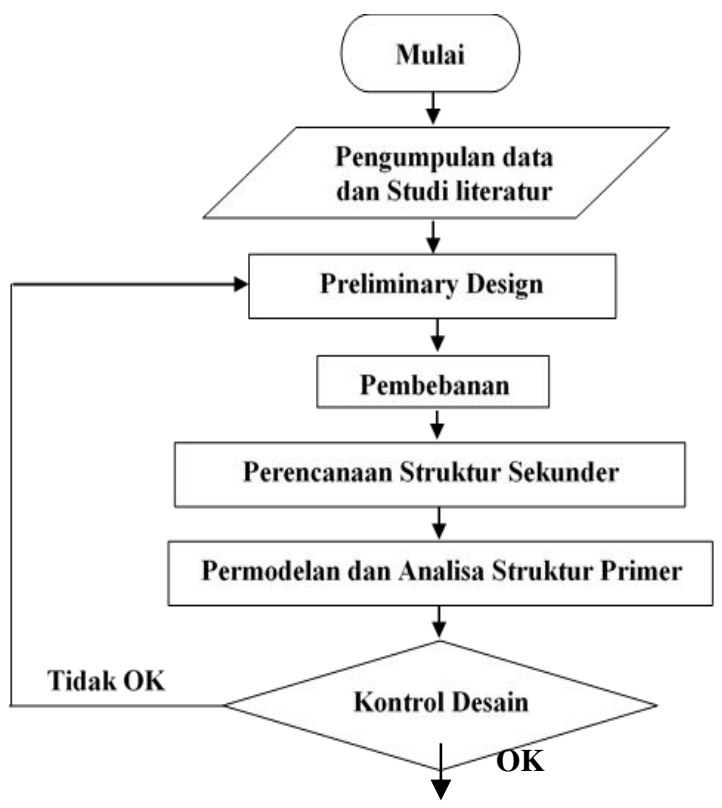



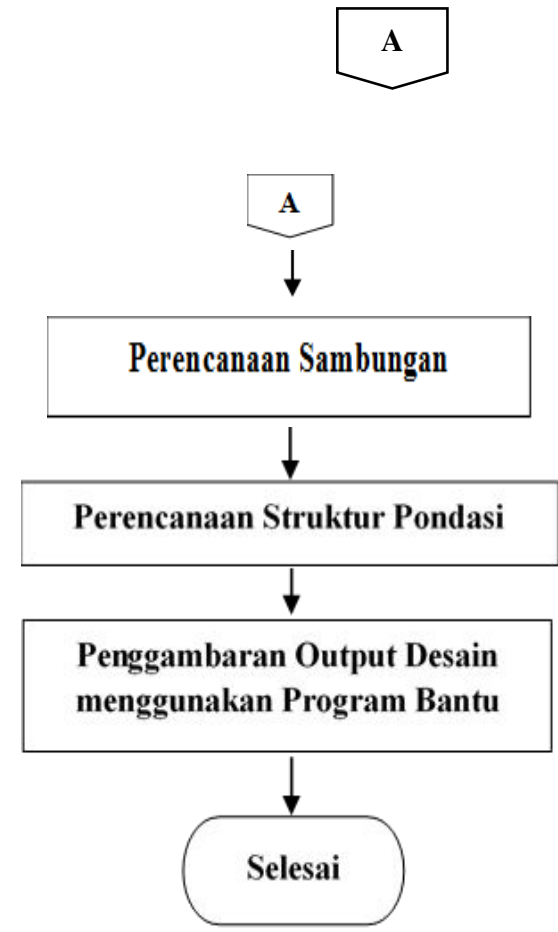

Gambar 4. Diagram Alir Penyelesaian Studi.

Adapun Studi ini akan dimodifikasi perencanaannya menggunakan material baja komposit dengan data-data sebagai berikut :

1. Nama Gedung : Apartemen Grand Kamala Lagoon

2. Lokasi Gedung : Bekasi, Jawa Barat

3. Fungsi Gedung : Apartemen

4. Tinggi Gedung : $72 \mathrm{~m}$

5. Jumlah Lantai : 23 lantai (3 lantai dasar, 19 lantai apartemen, dan 1 lantai atap)

6. Struktur Utama : Balok baja dengan dek dan kolom Concrete Filled Steel Tube

7. Sistem Struktur : Sistem Rangka Bresing Eksentris

\section{A. Perencanaan Struktur Sekunder}

\section{HASIL DAN PEMBAHASAN}

1. Pelat atap dan lantai

Pelat lantai atap dan lantai apartemen direncanakan menggunakan bondek dari Super Floor Deck dengan tebal $0,75 \mathrm{~mm}$. Hasil perhitungan struktur pelat ini tersaji pada tabel 2

Tabel 2.

Rekapitulasi Perhitungan Pelat Atap

\begin{tabular}{ccccc}
\hline \hline No & Bentang $(\mathrm{m})$ & Jumlah Tulangan $(\mathrm{n})$ & $\begin{array}{c}\text { Jarak } \\
(\mathrm{mm})\end{array}$ & $\begin{array}{c}\text { Tebal } \\
(\mathrm{mm})\end{array}$ \\
\hline 1 & 3,5 & 6 & 160 & 11 \\
2 & 3 & 5 & 200 & 9 \\
3 & 1,5 & 2 & 500 & 9 \\
\hline \hline
\end{tabular}

Tabel 3.

Rekapitulasi Perhitungan Pelat Lantai

\begin{tabular}{ccccc}
\hline \hline No & Bentang (m) & Jumlah Tulangan $(\mathrm{n})$ & $\begin{array}{c}\text { Jarak } \\
(\mathrm{mm})\end{array}$ & $\begin{array}{c}\text { Tebal } \\
(\mathrm{mm})\end{array}$ \\
\hline 1 & 3,5 & 9 & 110 & 11 \\
2 & 3 & 7 & 140 & 10 \\
3 & 1,5 & 2 & 500 & 9 \\
\hline \hline
\end{tabular}

2. Perencanaan Balok Sekunder
Balok sekunder direncanakan menggunakan wide flange (WF) BJ-41. Hasil perhitungan balok sekunder tersaji pada Tabel 4 dan Tabel 5.

Tabel 4.

Dimensi Balok Sekunder Atap

\begin{tabular}{ccc}
\hline \hline No & Bentang $(\mathrm{m})$ & Profil \\
\hline 1 & 10,6 & WF $450 \times 300 \times 10 \times 15$ \\
2 & 8,6 & WF $400 \times 200 \times 8 \times 13$ \\
3 & 6,6 & WF $300 \times 200 \times 8 \times 12$ \\
\hline \hline
\end{tabular}

Tabel 5.

Dimensi Balok Sekunder Atap

\begin{tabular}{ccc}
\multicolumn{3}{c}{ Dimensi Balok Sekunder Atap } \\
\hline \hline No & Bentang $(\mathrm{m})$ & Profil \\
1 & 10,6 & WF $450 \times 300 \times 11 \times 18$ \\
2 & 8,6 & WF $400 \times 300 \times 9 \times 14$ \\
3 & 6,6 & WF $300 \times 200 \times 9 \times 14$ \\
\hline \hline
\end{tabular}

3. Perencanaan Tangga dan Bordes

Tangga adalah sebuah konstruksi yang dirancang untuk menghubungi dua tingkat vertikal yang memiliki jarak satu sama lain.

Data Teknis Perencanaan Tangga

- Mutu baja = BJ-41

- Tinggi antar lantai $\quad=310 \mathrm{~cm}$

- Tinggi bordes $\quad=155 \mathrm{~cm}$

- Panjang tangga $\quad=300 \mathrm{~cm}$

- Lebar tangga $\quad=160 \mathrm{~cm}$

- Lebar bordes $\quad=175 \mathrm{~cm}$

- Lebar injakan (i) $\quad=30 \mathrm{~cm}$

- Tinggi Injakan (t) $\quad=15 \mathrm{~cm}$

- Lebar pegangan tangga $\quad=10 \mathrm{~cm}$

Tabel 6. Dimensi Tangga

\begin{tabular}{cll}
\hline \hline No & \multicolumn{1}{c}{ Jenis Struktur } & \multicolumn{1}{c}{ Ket. Profil } \\
\hline 1 & Balok Utama Tangga & WF200.100.4,5.7 \\
2 & Balok Penumpu Tangga & WF200.150.6.9 \\
3 & Pelat Bordes & Bondek, $\mathrm{t}=9 \mathrm{~cm}$ \\
4 & Pelat Tangga & Bondek, $\mathrm{t}=9 \mathrm{~cm}$ \\
\hline \hline
\end{tabular}

4. Perencanaan Lift

Pada bangunan ini menggunakan lift penumpang dengan data-data sebagai berikut (untuk lebih jelasnya lihat lampiran brosur lift) :

- $\quad$ Tipe lift

- Merek

: Passenger Elevators

- Kapasitas

: HYUNDAI

: 17 Orang / $1150 \mathrm{~kg}$

- Lebar pintu (opening width) : $1100 \mathrm{~mm}$

- Dimensi ruang luncur

(hoistway inside) 3 Car $\quad: 7850 \times 2030 \mathrm{~mm} 2$

- Dimensi sangkar (Car size)

Internal

: $2000 \times 1350 \mathrm{~mm} 2$

Eksternal

: 2100 x $1520 \mathrm{~mm} 2$

- Dimensi ruang mesin (3 Car) : 8300 x $3800 \mathrm{~mm} 2$

- Beban reaksi ruang mesin :

$\mathrm{R} 1=6600 \mathrm{~kg}$

$\mathrm{R} 2=5100 \mathrm{~kg}$

Dimensi Balok Penggantung Lift yaitu WF 600.300.12.20

B. Permodelan Struktur

1. Kontrol Partisipasi Massa

Partisipasi massa harus menyertakan jumlah ragam terkombinasi minimal $90 \%$ dari massa aktual yang berasal 
dari masing-masing arah horizontal dan orthogonal yang ditinjau [8].

Tabel 7.

Kontrol Nilai Partisipasi Massa

\begin{tabular}{ccccc}
\hline \hline OutputCase & Mode & Period & SumUX & Sum UY \\
\hline Text & Text & Sec & Unitless & Unitless \\
Modal & 7 & 0,429 & 0,9328 & 0,8772 \\
Modal & 8 & 0,422 & 0,933 & 0,9339 \\
\hline \hline
\end{tabular}

2. Kontrol Waktu Getar Alami Fundamental

Perkiraan periode alami fundamental (Ta) dalam detik, harus ditentukan dengan persamaan berikut:

$\mathrm{Ta}=\mathrm{Ct}$. hnx $; \mathrm{Ct}=0,0731 ; \mathrm{x}=0,75 ; \mathrm{hn}=72 \mathrm{~m}$

$\mathrm{Ta}=0,0731.117,60,75=2,611$ detik

Dengan nilai $\mathrm{SD} 1=0,7104$, maka $\mathrm{Cu}=1,4$

Sehingga periode sruktur yang diijinkan adalah :

$\mathrm{T}=\mathrm{Ta} . \mathrm{Cu}=1,806.1,4=2,529$ detik

Tabel 8.

Kontrol Waktu Getar Alami Fundamental

\begin{tabular}{lcccc}
\hline \multicolumn{4}{l}{ TABLE: Modal Periods and Frequencies } \\
Case & Mode & $\begin{array}{c}\text { Period } \\
\text { sec }\end{array}$ & $\begin{array}{l}\text { Frequency } \\
\text { cyc/sec }\end{array}$ & \\
\hline Modal & 1 & & 2,319 & 0,431 \\
Modal & 2 & & 2,295 & 0,436 \\
& & & & \\
Modal & 11 & & 0,286 & 3,491 \\
Modal & 12 & & 0,274 & 3,655 \\
\hline
\end{tabular}

Dari tabel diatas $\mathrm{Tc}=2,319 \mathrm{~s}$, maka berdasarkan kontrol aktu getar alami fundamental, nilai $\mathrm{T}$ masih lebih kecil dari $\mathrm{Cu}$.T. Jadi analisis struktur memenuhi syarat.

3. Kontrol Nilai Akhir Respon Spektrum

Kombinasi respons untuk gaya geser dasar ragam dinamik (Vt) harus lebih besar $85 \%$ dari gaya geser dasar $\operatorname{statik}(\mathrm{V})$ atau (Vdinamik $\geq 0,85$ Vstatik).

Tabel 9.

Kontrol Nilai Akhir Respon Spektrum

\begin{tabular}{lllll}
\multicolumn{4}{c}{ Kontrol Nilai Akhir Respon Spektrum } \\
\hline \hline Ket & $\begin{array}{l}\text { Vdinamik } \\
(\mathrm{kg})\end{array}$ & Vstatik $(\mathrm{kg})$ & $\begin{array}{l}\text { Vdinamik } \\
\text { Vstatik }\end{array}$ & $\geq$ \\
\hline RSX & 1072632 & \multirow{2}{*}{1231136} & Not OK & Not OK \\
RSY & 1017463 & & & . \\
\hline
\end{tabular}

Karena hasil tidak memenuhi maka simpangan antar lantai harus diperbesar dengan faktor skala $0,85 \frac{C s . W}{v}$.

Untuk simpangan arah $\mathrm{X}$ harus dikalikan:

$0,85 \frac{\text { Cs } . W}{v}=0,85 \times \frac{0,038 \times 37824649}{1072632}=1,14$

Untuk simpangan arah Y harus dikalikan

$0,85 \frac{\text { Cs. } W}{v}=0,85 \times \frac{0,025 \times 37824649}{1017463}=1,21$

4. Kontrol Simpangan (Drift)

Gempa menyebabkan struktur bertingkat rawan terhadap terjadinya simpangan horizontal (Drift). Dan apabila simpangan horizontal ini melebihi syarat aman yang telah ditentukan maka gedung akan mengalami keruntuhan.

\section{Perhitungan Struktur Primer}

\section{Link}

Balok link direncanakan menggunakan profil WF $600 \mathrm{x}$ $300 \times 12$ × 20. Dari hasil perhitungan didapat jenis link termasuk ke dalam link geser.

[7]

$$
\text { e } \quad=120 \mathrm{~cm}<1,6 . \mathrm{Mp} / \mathrm{Vp}=174,4 \mathrm{~cm}
$$

$$
\begin{aligned}
& \alpha=0,04 \text { radian }<\alpha \text { maks }=0,08 \text { radian } \\
& \mathrm{Nu}=4450 \mathrm{~kg}<0,15 \mathrm{Ny} \quad=72187 \mathrm{~kg} \\
& \mathrm{Vu}=51869 \mathrm{~kg}<\varnothing \mathrm{Vn}=88766 \mathrm{~kg}
\end{aligned}
$$

Untuk pengaku dengan panjang link < 1,6 . Mp / Vp, harus direncanakan memiliki pengaku antara. Untuk $\alpha=$ 0,04 radian maka:

$$
\begin{aligned}
S & =50,64-\left(\frac{0,04-0,02}{0,08-0,02}\right) \cdot(50,64-24,2) \\
& =40,52 \mathrm{~cm}
\end{aligned}
$$

Dipasang pengaku antara dengan jarak $30 \mathrm{~cm}$.

Tabel 10

KKontrol Simpangan Arah-Y Gempa Arah Y

\begin{tabular}{|c|r|c|c|c|c|c|c|}
\multicolumn{7}{|c|}{ Kontrol Simpangan Arah-Y Gempa Arah Y } \\
\hline Lantai & Rasio Drift & $\begin{array}{c}\text { Elevasi } \\
(\mathrm{mm})\end{array}$ & $\delta$ xe $(\mathrm{mm})$ & $\delta \times(\mathrm{mm})$ & $\begin{array}{c}\delta \times x \text { SF } \\
(\mathrm{mm})\end{array}$ & $\Delta a(\mathrm{~mm})$ & Kontrol \\
\hline Roof & 0,0005 & 3100 & 1,56 & 6,22 & 7,53 & 62 & OK \\
\hline 19 & 0,0006 & 3100 & 1,82 & 7,27 & 8,79 & 62 & OK \\
\hline 18 & 0,0007 & 3100 & 2,17 & 8,69 & 10,52 & 62 & OK \\
\hline 17 & 0,0008 & 3100 & 2,53 & 10,12 & 12,24 & 62 & OK \\
\hline 16 & 0,0009 & 3100 & 2,87 & 11,48 & 13,89 & 62 & OK \\
\hline 15 & 0,0010 & 3100 & 3,18 & 12,72 & 15,39 & 62 & OK \\
\hline 14 & 0,0011 & 3100 & 3,46 & 13,84 & 16,74 & 62 & OK \\
\hline 13 & 0,0012 & 3100 & 3,71 & 14,84 & 17,96 & 62 & OK \\
\hline 12 & 0,0013 & 3100 & 3,93 & 15,72 & 19,03 & 62 & OK \\
\hline 11 & 0,0013 & 3100 & 4,13 & 16,50 & 19,97 & 62 & OK \\
\hline 10 & 0,0014 & 3100 & 4,30 & 17,20 & 20,81 & 62 & OK \\
\hline 9 & 0,0014 & 3100 & 4,45 & 17,81 & 21,55 & 62 & OK \\
\hline 8 & 0,0015 & 3100 & 4,59 & 18,36 & 22,22 & 62 & OK \\
\hline 7 & 0,0015 & 3100 & 4,71 & 18,85 & 22,81 & 62 & OK \\
\hline 6 & 0,0016 & 3100 & 4,82 & 19,27 & 23,32 & 62 & OK \\
\hline 5 & 0,0016 & 3100 & 4,90 & 19,62 & 23,74 & 62 & OK \\
\hline 4 & 0,0016 & 3100 & 4,96 & 19,83 & 23,99 & 62 & OK \\
\hline 3 & 0,0016 & 3100 & 4,96 & 19,85 & 24,02 & 62 & OK \\
\hline 2 & 0,0016 & 3100 & 4,94 & 19,77 & 23,92 & 62 & OK \\
\hline 1 & 0,0016 & 3100 & 5,11 & 20,44 & 24,73 & 62 & OK \\
\hline Transfer & 0,0017 & 5000 & 8,35 & 33,38 & 40,39 & 100 & OK \\
\hline UG & 0,0009 & 5000 & 4,45 & 17,78 & 21,51 & 100 & OK \\
\hline & & & & & & & \\
\hline
\end{tabular}

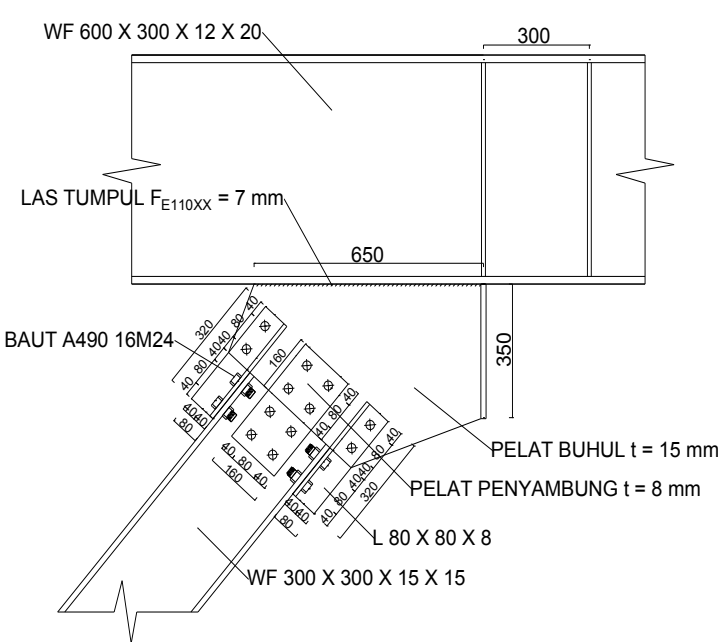

Gambar 5. Elemen Link dan Pengaku.

\section{Balok diluar Link}

Balok link direncanakan menggunakan profil WF $600 \mathrm{x}$ 300 x 12 x 20. Berdasarkan SNI 03-1729-2002 Pasal 15.13.6.2, kuat perlu balok yang terletak diluar link harus ditentukan berdasarkan gaya- gaya yang ditimbulkan paling tidak 1,1 kali kuat geser nominal link sebesar Ry.Vn. 
Kontrol interaksi geser lentur yang terjadi:

$$
\begin{array}{r}
\frac{M u}{\emptyset \cdot M n}+0,625 \frac{V u}{\emptyset \cdot V n} \leq 1,375 \\
1,105 \leq 1,375 \quad(\mathrm{OK})
\end{array}
$$

3. Bresing

Bresing direncanakan menggunakan profil WF $300 \mathrm{x}$ 300 x 15 x 15. Berdasarkan SNI 03-1729-2002 Pasal 15.13.6.1, kuat kombinasi- aksial- dan lentur perlu pada batang bresing harus sebesar 1,25 Ry Vn.

$$
\begin{aligned}
& \mathrm{Vu}=1,25 . \mathrm{Ry} . \mathrm{Vn} \text { [7] } \\
& =1,25 \cdot 1,5 .(0,6 \cdot 2500 .(58,8-2 \cdot 2) \cdot 1,2) \\
& =184950 \mathrm{~kg} \\
& P_{u} \text { tekan }=P_{u} \text { tarik }=\frac{V_{u}}{\sin \alpha}=\frac{184950}{0,88}=210193 \mathrm{~kg} \\
& \text { Bressing tarik } \\
& \phi_{c} P_{n}=\phi_{c} \cdot R_{y} \cdot F_{y} \cdot A g \\
& =0,9 \cdot 1,5 \cdot 2500 \cdot 134,8=454950 \mathrm{~kg} \\
& \phi_{c} P_{n}>P u \rightarrow 454950 \mathrm{~kg}>210193 \mathrm{~kg}(O K) \\
& \text { Bresing tekan } \\
& \phi_{c} P_{n}=0,85 \cdot 1,1 \cdot R_{y} \cdot F_{y} \cdot A g / F_{c r} \\
& =0,85 \cdot 1,1 \cdot 1,52500 \cdot 134,8 / 1,416=392668,4 \mathrm{~kg} \\
& \phi_{c} P_{n}>P u \rightarrow 392668,4 \mathrm{~kg}>210193 \mathrm{~kg}(O K)
\end{aligned}
$$

4. Balok

Balok direncanakan menggunakan profil WF 600 x 300 x 12 x 17. Dari output ETABS 2016 diperoleh gaya dalam yang dipakai dalam desain adalah:

$$
\begin{aligned}
& \mathrm{Mu}=23435 \mathrm{~kg} \cdot \mathrm{m} \leq \varnothing \mathrm{Mn}=85095 \mathrm{~kg} \cdot \mathrm{m} \\
& \mathrm{Vu}=10068,7 \mathrm{~kg} \geq \emptyset \mathrm{Vn}=94284 \mathrm{~kg} \\
& \mathrm{f} 0=0,411 \mathrm{~cm} \leq \mathrm{f} \text { ijin }=2,22 \mathrm{~cm}
\end{aligned}
$$

5. Kolom

Kolom direncanakan menggunakan profil HSS $700 \mathrm{x}$ 700 × 28 x 28 dengan kontrol kuat nominal penampang sebagai berikut:

Rumus Interaksi:

\begin{tabular}{|c|c|c|c|c|}
\hline \multicolumn{2}{|c|}{ Elemen } & \multirow{2}{*}{$\begin{array}{l}\text { Profil Siku } \\
\text { L60.60.6 }\end{array}$} & $\mathrm{D}(\mathrm{mm})$ & \multirow{2}{*}{$\frac{n(j b)}{2}$} \\
\hline $\begin{array}{lr}\text { Balok anak } \\
\text { lantai -balok }\end{array}$ & Badan B.Anak & & 16 & \\
\hline Induk & Badan B.Induk & L60.60.6 & 16 & 2 \\
\hline $\begin{array}{l}\text { Balok utama } \\
\text { tangga } \\
\text { penumpu } \\
\text { tangga }\end{array}$ & $\begin{array}{l}\text { Badan B.Utama } \\
\text { Tangga } \\
\text { Badan } \\
\text { B.Penumpu } \\
\text { Tangga }\end{array}$ & L60.60.6 & 8 & 3 \\
\hline $\begin{array}{l}\text { Balok } \\
\text { penumpu } \\
\text { tangga } \\
\text { kolom }\end{array}$ & $\begin{array}{l}\text { Badan } \\
\text { B.Penumpu } \\
\text { Tangga }\end{array}$ & L60.60.6 & $\begin{array}{l}10 \\
\text { Las } \\
\mathrm{mm}\end{array}$ & 2 \\
\hline
\end{tabular}

$$
\begin{aligned}
& \frac{P u}{\varphi P n}=0,474>0,2 \rightarrow \text { Interaksi } 1 \\
& \quad \text { Kontrol Interaksi "Balok }- \text { Kolom" } \\
& \frac{P_{u}}{\emptyset P_{n}} \geq 0,2 \rightarrow \frac{P_{u}}{\emptyset P_{n}}+\frac{8}{9}\left(\frac{M_{u x}}{\emptyset_{b} M_{n x}}+\frac{M_{u y}}{\emptyset_{b} M_{n y}}\right) \leq 1,0
\end{aligned}
$$

$$
0,744 \leq 1,0(\mathrm{OK})
$$

Hasil seluruh perhitungan struktur primer akan disajikan pada Tabel 11

Tabel 11.

\begin{tabular}{|c|c|c|c|c|}
\hline Elemen & $\begin{array}{c}\mathrm{D} \\
\text { badan } \\
(\mathrm{mm})\end{array}$ & $\begin{array}{c}\text { n } \\
\text { badan } \\
\text { (buah) }\end{array}$ & $\begin{array}{c}\mathrm{D} \\
\text { sayap } \\
(\mathrm{mm})\end{array}$ & $\begin{array}{c}\mathrm{n} \\
\text { sayap } \\
\text { (buah) }\end{array}$ \\
\hline $\begin{array}{l}\text { Balok diluar Link } X \text { dan } \\
\text { Kolom }\end{array}$ & 20 & 4 & 30 & 12 \\
\hline $\begin{array}{l}\text { Balok diluar Link Y dan } \\
\text { Kolom }\end{array}$ & 20 & 4 & 30 & 14 \\
\hline Bresing X & 24 & 8 & 24 & 8 \\
\hline Bresing Y & 24 & 8 & 24 & 12 \\
\hline Balok Induk X dan Kolom & 20 & 3 & 30 & 10 \\
\hline Balok Induk Y dan Kolom & 20 & 4 & 30 & 14 \\
\hline Antar Kolom & \multicolumn{4}{|c|}{ Las tumpul penetrasi penuh $1,6 \mathrm{~cm}$} \\
\hline Kolom - Base Plate & $\mathrm{T}$ Plat $=$ & $60 \mathrm{~mm}$ & $\begin{array}{l}\mathrm{N} \\
\text { angkur }\end{array}$ & $8 \mathrm{M} 22$ \\
\hline
\end{tabular}

Hasil Perhitungan Struktur Primer

\begin{tabular}{cc}
\hline \hline Elemen & Dimensi \\
\hline Link $X$ & WF 600.300.12.20 \\
Link $Y$ & WF 700.300.13.24 \\
Balok Diluar Link X & WF 600.300.12.20 \\
Balok Diluar Link $Y$ & WF 700.300.13.24 \\
Bresing Arah X & WF 300.300.15.15 \\
Bresing Arah Y & WF 300.300.11.17 \\
Balok Induk Memanjang & WF 600.300.12.17 \\
Balok Induk Melintang & WF 600.300.14.23 \\
Kolom & HSS 700.700.28.28 \\
\hline \hline
\end{tabular}

D. Perencanaan Sambungan

1. Sambungan Struktur Sekunder
Pada perencanaan sambungan, direncanakan baut dengan mutu BJ50 dan pelat penyambung profil siku dengan mutu BJ41. Hasil perhitungan sambungan struktur sekunder terlampir pada Tabel 12 .

Tabel 12.

Sambungan Struktur Sekunder

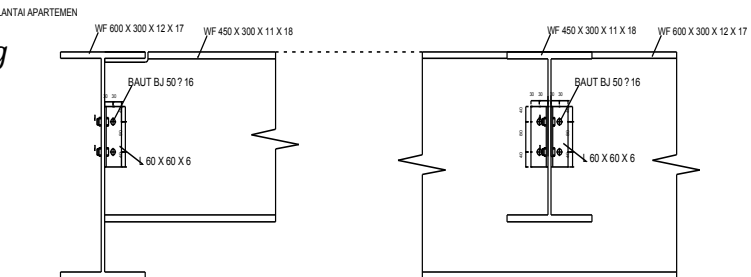

Gambar 6. Sambungan Balok Anak dan Balok Induk.

\section{Sambungan Struktur Primer}

Pada perencanaan sambungan, direncanakan baut dengan mutu A490, Mutu las FE70xx dan FE110XX, dan pelat penyambung mutu BJ-41. Hasil perhitungan sambungan struktur primer tersaji pada Tabel 13.

Tabel 13.

Sambungan Struktur Prime 


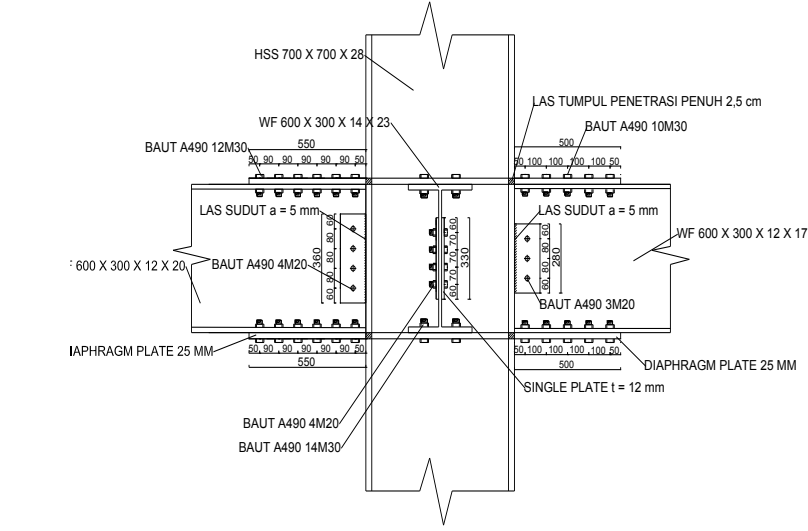

Gambar 7. Sambungan Kolom dan Balok Induk

\section{E.Perhitungan Struktur Bawah}

1. Pondasi Tiang Pancang

Pondasi yang digunakan pada perencanaan gedung perkantoran berasal dari tiang pancang beton (Concrete Pile) dari produk dari PT. WIKA Beton dengan spesifikasi adalah sebagai berikut:

$\begin{array}{lll}\text { - } & \text { Diameter tiang } & : 600 \mathrm{~mm} \\ \text { - } & \text { Tebal tiang } & : 100 \mathrm{~mm}\end{array}$

$\begin{array}{lll}\text { Klasifikasi } & : \text { A1 } \\ \text { - } \quad \text { Concrete cross section } & : 1570,8 \mathrm{~cm} 2 \\ \text { - } \quad \text { Berat } & : 393 \mathrm{~kg} / \mathrm{m} \\ \text { - } & \text { Bending moment crack } & : 17 \mathrm{tm} \\ \text { - } \quad \text { Bending momen ultimate } & : 25,5 \mathrm{tm} \\ \text { - } & \text { Allowable axial load } & : 252,7 \mathrm{tm}\end{array}$

Daya dukung ijin dari satu tiang pancang yang berdiri sendiri adalah

$$
\begin{aligned}
& P_{i j \text { in } 1 \text { tiang }}=\frac{Q u}{S F}=\frac{367,56+401,53}{3} \\
&=256,36 \text { ton } \\
& P_{i j \text { in } 1 \text { tiang }} \text { pakai }=252,7 \text { ton }
\end{aligned}
$$

Kontrol beban tetap

Pmax $=140,5$ ton $<$ Qijin $=252,7 \times 0,65=165,7$ ton $(\mathrm{OK})$

\section{Perencanaan Poer}

Untuk penulangan lentur, poer dianalisa sebagai balok kantilever dengan perletakan jepit pada kolom. Dan beban yang bekerja adalah beban terpusat di tiang kolom yang menyebabkan reaksi pada tanah dan berat sendiri poer.

Berikut adalah hasil perhitungan untuk dimensi poer :

Tabel 14.

Rekapitulasi Dimensi Poer

\begin{tabular}{|c|c|c|c|c|c|c|c|}
\hline \multirow{2}{*}{ Tipe } & \multirow{2}{*}{ Dimensi } & \multirow{2}{*}{$\begin{array}{c}\text { Jumlah } \\
\text { tiang }\end{array}$} & \multirow{2}{*}{$\begin{array}{c}\text { Diameter } \\
\text { Pancang }\end{array}$} & \multicolumn{2}{|c|}{ Tulangan X } & \multicolumn{2}{|c|}{ Tulangan Arah Y } \\
\cline { 5 - 8 } & & & & Atas & Bawah & Atas & Bawah \\
\hline PC 1 & $3,6 \times 3,6 \times 1$ & 9 & 60 & D16-150 & D22-150 & D16-150 & D22-150 \\
\hline PC 2 & $4,8 \times 2,4 \times 1,5$ & 8 & 60 & D22-250 & D29-250 & D22-250 & D29-250 \\
\hline PC 3 & $2,4 \times 4,8 \times 1,5$ & 8 & 60 & D22-250 & D29-250 & D22-250 & D29-250 \\
\hline
\end{tabular}

\section{Perencanaan Kolom Pedestal}

Besarnya gaya - gaya dalam kolom diperoleh dari hasil analisis ETABS 2016 adalah:

$$
\begin{array}{ll}
\mathrm{Mu} & =20180,6 \mathrm{~kg} \cdot \mathrm{m} \\
\mathrm{Pu} & =795617,9 \mathrm{~kg}=7797056 \mathrm{~N} \\
\mathrm{Vu} & =15854,96 \mathrm{~kg}=158549,6 \mathrm{~N}
\end{array}
$$

Dimensi kolom pedestal $1000 \mathrm{~mm}$ x $1000 \mathrm{~mm}$.
As $=0,0108.1000 .939=10141,2 \mathrm{~mm} 2$

Dipasang tulangan 28D22, As $=10643,7 \mathrm{~mm} 2$

Dipasang merata 4 sisi dengan sengkang $\varnothing 10-150$.

\section{Perencanaan Tie Beam}

Tie Beam direncanakan menggunakan tulangan baja, hal tersebut dilakukan karena Tie Beam menerima kombinasi beban aksial tekan dan lentur.

$$
\begin{aligned}
& \text { Gaya aksial kolom }=795617,94 \mathrm{~kg} \\
& \begin{array}{l}
\mathrm{Pu}=10 \% \times 795617,94 \mathrm{~kg} \\
\quad=79561,8 \mathrm{~kg} \rightarrow 795618 \mathrm{~N}
\end{array} \\
& \text { Dari perhitungan didapat } \rho=0,0033 \\
& \text { Dipasang tulangan }=5 \mathrm{D} 16(A s=1005,31 \mathrm{~mm} 2) \\
& \text { dan sengkang } \varnothing 10-300 \mathrm{~mm}
\end{aligned}
$$

\section{KESIMPULAN DAN SARAN}

\section{A. Kesimpulan}

Sesuai dengan tujuan penulisan studi ini, maka dapat ditarik kesimpulan sebagai berikut:

1. Hasil perhitungan pada struktur sekunder telah memenuhi syarat terhadap kontrol kuat penampang, kontrol geser dan lendutan yang mengacu kepada SNI 1729-2015.

2. Dari kontrol yang dilakukan, kontrol partisipasi massa, kontrol waktu getar alami fundamental, kontrol nilai akhir respon spektrum, kontrol simpangan (drift)) struktur yang direncanakan berada di kota Bekasi telah memenuhi syarat yang terdapat pada SNI 1729-2015 (analisis struktur dapat digunakan)

3. Hasil analisa struktur primer yang dilakukan telah memenuhi syarat terhadap kontrol kuat penampang, kontrol geser, kontrol sudut rotasi link, kontrol interaksi geser lentur dan lendutan.

4. Perhitungan pada struktur bawah telah memenuhi persyaratan dimensi dan kontrol akibat pons.

\section{B. Saran}

Diharapkan dilakukan studi yang mempelajari tentang perencanaan struktur Eccentrically Braced Frames (EBF) lebih dalam dengan mempertimbangkan aspek teknis, ekonomis, dan estetika dengan tetap mengacu kepada aturan yang berlaku. Diharapkan perencanaan dapat dimodelkan semirip mungkin dengan kondisi sesungguhnya di lapangan.

\section{DAFTAR PUSTAKA}

[1] A. Fauzi, "Modifikasi Perencanaan menggunakan Sistem Rangka Bresing Konsentris Khusus pada Gedung Apartemen Metropolis," Surabaya, 2013.

[2] E. P. Popov and C. W. Roeder, "Design of an Eccentrically Braced Steel Frame," AISC Eng. Journal. 3rd Quart., vol. 15, no. 3, 1978.

[3] I. Fihari, "Analisis Pelat Buhul Struktur Rangka Baja Berpengaku Eksentrik," Yogyakarta, 2010.

American Institute of Steel Construction, "Seismic Provision for Structural Steel Buildings," 2010.

[5] E. P. Popov and E. M. D, "Seismic Eccentrically Braced Frames," J. Constr. Steel Res., 1988.

[6] Engelhardt and D. Michael, "Design Of Seismic Resistant Steel Building Structures," USA, 2007.

[7] Badan Standarisasi Nasional, "Tata Cara Perencanaan Struktur Baja Untuk Bangunan Gedung (SNI 03-1729-2002),” Bandung, 2002

[8] Badan Standarisasi Nasional, "Tata Cara Perencanaan Ketahanan 
Gempa Untuk Bangunan Gedung (SNI 03-1726-2012),' Bandung, 2012.

[9]
Struktural (SNI 03-1729-2015),” Bandung, 2015.

[10] H. Wahyudi, Daya Dukung Pondasi Dalam. Surabaya: Jurusan Teknik Sipil FTSP - ITS, 1999. 